\title{
Acute myelomonocytic leukaemia following atypical congenital rubella
}

\author{
S J Kelly, T Gibbs, C H Cheetham
}

\begin{abstract}
The child of a woman immunised against rubella presented at 5 months with developmental delay and recurrent infection; she was shown to have congenital rubella. At 15 months she developed acute myelomonocytic leukaemia (AMML). Rubella is difficult to diagnose after immunisation. AMML has not been previously described in association with congenital rubella, as far as is known.
\end{abstract}

(F Clin Pathol 1993;46:764-765)

Acute non-lymphocytic leukaemia (ANLL) accounts for $15-20 \%$ of childhood leukaemias. A wide variety of single gene traits, constitutional, and familial conditions have been associated with an increased risk of developing such leukaemias and other haematological malignancies. ${ }^{1}$ Maternal viral infection during pregnancy has not been clearly associated with increased incidence of childhood leukaemia. ${ }^{23}$ Adelstein and Donovan found no evidence of a link between congenital rubella and childhood malignancy, although only deaths over the age of 2 years were analysed. An association with chicken pox, however, was considered a possibility. One case of lymphoblastoma has been reported after maternal rubella. ${ }^{4}$ We report the case of a child with an atypical congenital rubella syndrome who developed acute myelomonocytic leukaemia at the age of 15 months.

\section{Case report}

The patient was the fourth child of a 39 year old woman. Amniocentesis during pregnancy had shown a normal female karyotype. The mother was exposed during the second month of pregnancy to rubella infection which had been contracted by her older children. She was thought to be immune following immunisation 10 years earlier with Cendevac after the birth of her first child, and her anti-rubella IgG titre at this time was compatible with immunity (table). The baby was well at delivery but presented at 2 weeks of age with a facial cellulitis due to Staphylococcus aureus infection. She continued to be unwell intermittently and presented to hospital again at 5 months with poor weight gain, fever, and rash. She had pronounced hepatosplenomegaly, was underweight $(4 \cdot 26$ $\mathrm{kg}$ ), and had severe developmental delay with a developmental quotient of $41 \%$ (Griffiths'
Mental Development Assessment). Vision and hearing were both normal. Her fever responded to antibiotics; pneumococci were grown from a surface swab.

Further investigation indicated a mild neutropenia $\left(0.9-1.6 \times 10^{9} / 1\right)$ : liver function tests were normal and immunoglobulins and white cell enzyme estimations were within the normal range. A liver biopsy specimen was also normal. A bone marrow aspirate (figure) showed an active marrow with no evidence of a storage disorder, mildly iron deficient erythropoiesis, and left shifted myelopoiesis compatible with a neutropenia secondary to splenomegaly. There was no evidence of dysplasia. Screening tests for congenital infections showed a grossly raised rubella IgM titre. Retrospective analysis of the mother's serum taken at eight weeks of pregnancy showed a raised rubella IgM titre compatible with active infection (table). Atypical congenital rubella syndrome was diagnosed.

Her subsequent progress was marred by recurrent upper respiratory tract infection, feeding difficulties, and poor weight gain. At 10 months there was some improvement and her hepatosplenomegaly had regressed.

At 15 months she was seen with a three week history of increased irritability and a mass behind the left ear. Examination showed a lethargic infant with a $3 \mathrm{~cm}$ firm swelling over the left mastoid process, moderate hepatosplenomegaly, periorbital bruising on the right, and a few purpuric spots on the trunk. A skull $x$ ray picture showed a soft tissue swelling in the left temporal region with no abnormality of the mastoid bone. A full blood count showed a haemoglobin of $67 \mathrm{~g} / \mathrm{l}$, a white cell count of $51 \times 10^{9} / 1$ and a platelet count of $22 \times 10^{9} / 1$. The film was compatible with acute myelomonocytic leukaemia (AMML) with $30 \%$ blast cells (figure). A bone marrow aspirate showed a hypercellular marrow with $60 \%$ blast cells, and histochemistry confirmed AMML. Subsequent chromosomal analysis of the peripheral blood blast cells identified an inverted chromosome 16 abnormality.

\begin{tabular}{ll} 
Anti-rubella titres \\
\hline Mother & At previous antenatal assessment IgG 13 \\
IU/ml (information recovered retrospectively) \\
At eight weeks of pregnancy IgG $14 \mathrm{~mm}$ zone \\
by serum radial haemolysis $(15 \mathrm{IU} / \mathrm{ml}$ cutoff \\
zone at $8.5 \mathrm{~mm}$ ) \\
IgM $0.353 \mathrm{EIA}$ units with a cutoff of 0.242 \\
Baby & EIA. \\
& At 5 months IgM 0.636 EIA units with a cut \\
& off at 0.242 EIA.
\end{tabular}




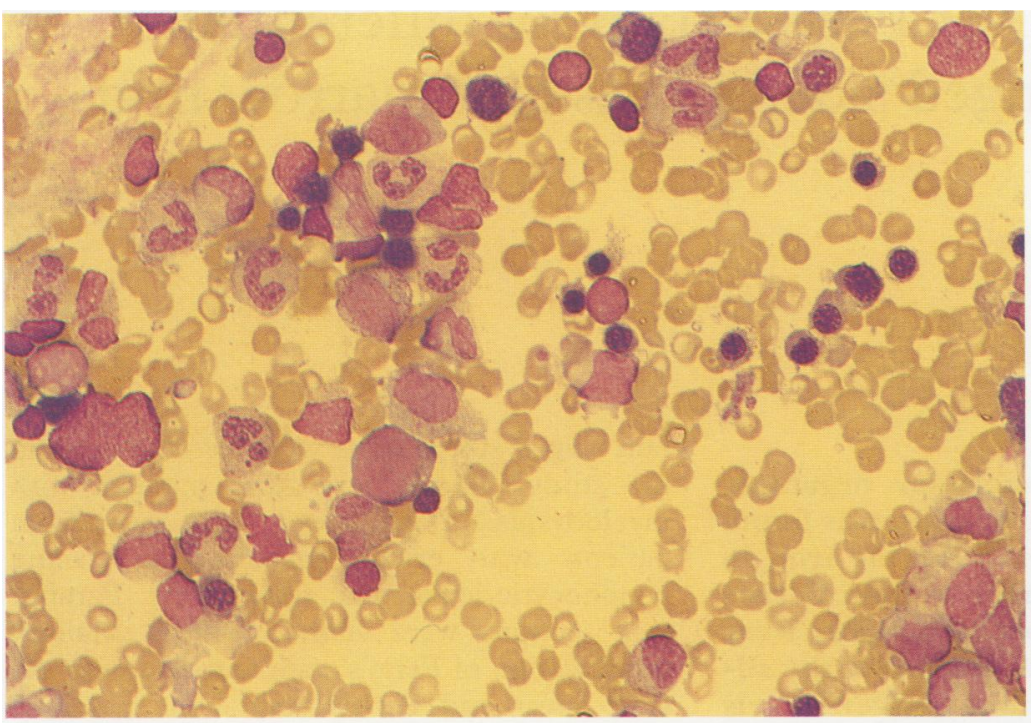

(A)

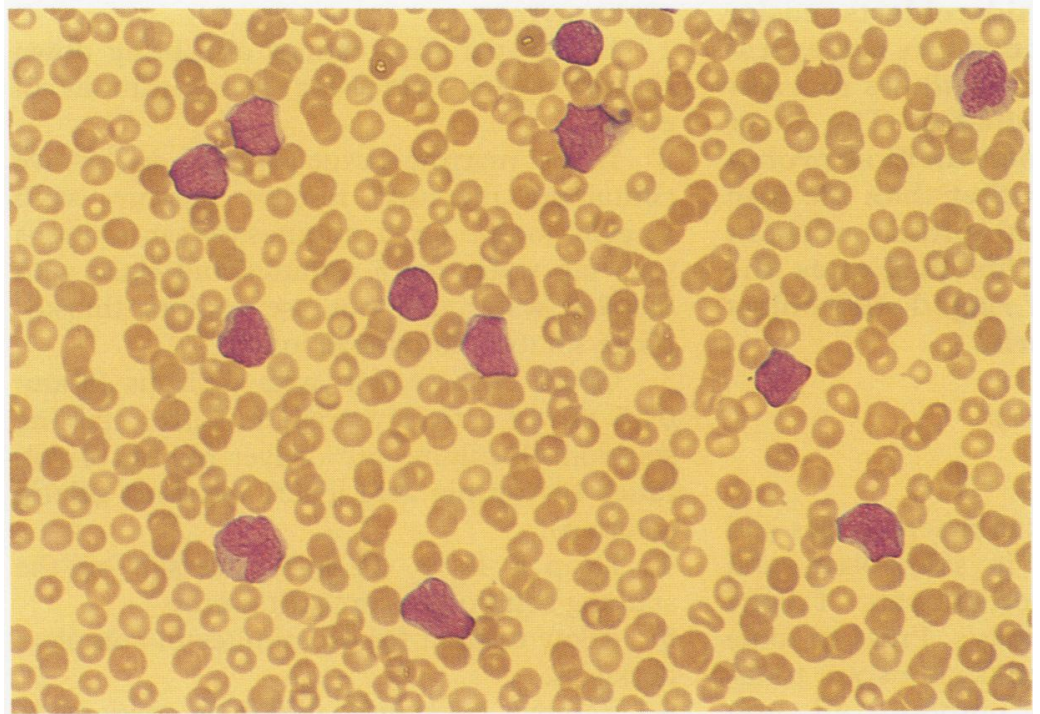

(B)

Figure (A) Bone marrow aspirate at 5 months. (B) Peripheral blood smear at 15 months showing $A M M L$ child was extensively investigated at the age of 5 months for problems eventually attributed to congenital rubella on good serological evidence, although she had few of the classic features of this condition. This presentation highlights the contentious issue of rubella screening and the value of induced immunity in the protection of the pregnant mother and her child. It illustrates the need for paired serological investigations in patients exposed to rubella in pregnancy, despite possible immunity, as reinfection has been clearly described and may cause congenital rubella infection. ${ }^{5}$ The other investigations performed at this time clearly ruled out many of the known conditions that predispose to childhood leukaemia, such as Down's syndrome and hypogammaglobulinaemia and made many others unlikely (such as Fanconi's and Bloom's syndrome). Examination of the bone marrow aspirate also ruled out other acquired states such as a myelodysplasia. She was also known to have a normal constitutional chromosomal complement and had developed, in the peripheral blood blasts, an acquired chromosomal abnormality, the inverted 16 , which is strongly associated with AMML. ${ }^{6}$ In patients with adult leukaemia this abnormality is often associated with abnormal eosinophils in the marrow, but these were not apparent in this case. AMML in infants often gives rise to both central nervous system and soft tissue disease and the prognosis is poor. ${ }^{7}$ This child was thought to have a particularly poor outlook because of the high initial white cell count, the possibility of central nervous disease, and the history of recurrent infections.

It is not known for certain if this child's leukaemia can be attributed to the underlying congenital rubella as this particular association has not been noted before. Most other predisposing conditions were precluded by the extensive investigations she underwent at the age of 5 months, and therefore such an association cannot be entirely dismissed.

In view of the overall poor prognosis of this child and in agreement with the parents, intensive chemotherapy was not pursued. She received blood product support and palliative radiotherapy to the head, following the development of a right ptosis and nasal obstruction. Two months later she developed obstructive jaundice and coma and died peacefully at home. Post mortem examination was not performed.

\section{Discussion}

Acute leukaemia in childhood has not previously been reported in association with congenital rubella syndrome and this case has some particularly interesting aspects. The
$1 \mathrm{Li}$ FP, Bader $\mathrm{JL}$. Oncology-epidemiology of selected childhood cancers In: Nathan DG, Oski FA, eds. Haematology of infancy and childhood: Philadelphia: WB Saunders, 1987:918-41.

2 Adelstein AM, Donovan JW. Malignant disease in children whose mothers had chickenpox, mumps or rubell in pregnancy. Br Med F 1972;iv:629-31.

3 Fedrick J, Alberman ED. Reported Influenza in pregnancy and subsequent cancer in the child. $\mathrm{Br}$ Med $\mathrm{F}$ 1972;ii: 485-8.

4 Stewart A, Webb J, Hewitt D. A survey of childhood malignancies. Br Med f 1958;1:1497-508.

5 Best JM, Banatvala JE, Morgan-Capner P, Miller E. Fetal infection after maternal reinfection with rubella: criteria for defining reinfection. Br Med f 1989;299:773-5.

6 Le Beau MM, Larson RA, Bitter MA, Vardiman JW, Golomb HM, Rowley JD. Association of an inversion of chromosome 16 with abnormal marrow eosinophils in acute myelomonocytic leukaemia: a unique cytogeneticclinicopathologic association. N Engl 7 Med 1983; 309:630-6.

7 Chessels JM, O'Callaghan U, Hardisty RM. Acute myeloid leukaemia in childhood: clinical features and prognosis. Br f Haematol 1986;63:555-64. 